\title{
LAS COMISARIAS RURALES DEL ANTIGUO TERRITORIO DE \\ COLONIZACIÓN DE MAGALLANES (1902-1927)
}

\author{
MATEO MARTINIC B." Y DUNCAN S. CAMPBELL"
}

\begin{abstract}
RESUMEN
El infrapoblamiento del vasto ámbito rural de Magallanes durante el período de consolidación de la colonización exigió por razones de control gubernativo y seguridad pública la creación de "comisarías rurales", como entidades sui generis y ad hoc con vigencia excepcional e irrepetida en el ordenamiento político-administrativo chileno durante un cuarto de siglo, hasta la institución de la Provincia de Magallanes a contar del 1ํ de enero de 1928. El artículo da cuenta de los antecedentes que motivaron la creación de esas unidades administrativas intraterritoriales, de su número y características, y de los titulares conocidos de las mismas. Se particulariza la información con lo acontecido en la Comisaría de Punta del Monte entre 1902 y 1907 sobre la base del diario de vida de John Mac Lean.
\end{abstract}

PALABRAS CLAVES: Magallanes, colonización, organización administrativa, vida rural.

\section{THE “OFFICE OF THE RURAL SHERIFF” IN THE OLD TERRITORY OF MAGALLANES (1902-1927)}

\section{ABSTRACT}

In order to ensure government control and public safety during the early settlement period, the vast, largely uninhabited, rural areas of Magallanes required the creation of a sui generis, ad hoc entity: the Office of the Rural Sheriff, unique within the Chilean political-administrative framework. Several such Offices functioned in Magallanes for a quarter of a century, until the Territory became a Province on January $1^{\text {st }}, 1928$. This article presents the background for the creation of these administrative Offices; provides information on their number, location and characteristics; and identifies known Officeholders of the period.

Examples are drawn from the correspondence of Sheriff John Mac Lean, of the Punta del Monte district, during the period 1902-1907.

KEYWORDS: Magallanes, settlement period, administrative organization, rural life.

Profesor emérito, Centro de Estudios del Hombre Austral, Instituto de la Patagonia, Universidad de Magallanes, Punta Arenas, Chile. Correo electrónico: mateo.martinic@umag.cl

* Investigador particular. Correo electrónico: dg@patbrit.org 


\section{INTRODUCCIÓN}

Ocupado el territorio de la Patagonia austral y la Tierra del Fuego por parte de la República de Chile a partir del 21 de setiembre de 1843, el establecimiento permanente que surgió en consecuencia, primero en Fuerte Bulnes y a partir del 18 de diciembre de 1848 en Punta Arenas, lo hizo bajo la figura administrativa de Colonia de Magallanes. Esta situación se mantuvo hasta agosto de 1853, cuando por decreto supremo de 8 de dicho mes, el Supremo Gobierno creó el Territorio de Colonización de Magallanes con el fin de fomentar su poblamiento y desarrollo. Esta nueva entidad era especial por cuanto no tenía respaldo constitucional y parece haber surgido de una necesidad circunstancial y, por tanto, transitoria. Sólo sabemos de otros dos casos históricos, como fueron los correspondientes a los Territorios de Colonización de Llanquihue (1853-1861) y de Aysén (1927).

Inicialmente de superficie extensa pero indeterminada, como que cubría toda la parte austral del continente desde Chiloé al sur, por el lado del océano Pacífico, y el territorio de la Patagonia oriental o atlántica, además de la Tierra del Fuego y su archipiélago, la cabida de la colonia magallánica comenzó a acotarse, primero por la ley de 30 de agosto de 1848 que delimitó la jurisdicción marítima chilena con la creación de tres gobernaciones, correspondiendo la meridional de ellas a Magallanes, desde la península Tres Montes (47응 por el lado occidental, hasta la boca del río Negro por el oriental ${ }^{1}$; $y$, después, a contar del 23 de julio de 1881, por el Tratado de Límites suscrito entre Chile y la República Argentina que, en lo que interesa, puso fin a la cuestión de dominio trabada entre ambos en 1847 estableciendo la división de las correspondientes jurisdicciones. De esa manera, el Territorio de Colonización de Magallanes quedó con una superficie estimada en no menos de $170.000 \mathrm{~km} 2^{2}$.

1 Hasta ese punto se extendía entonces la pretensión jurisdiccional chilena en un territorio como era el patagónico oriental, que aunque incluido en los títulos históricos heredados de España no había sido delimitado formalmente entre la República de Chile y la Confederación Argentina, estado que también había formulado alegaciones de dominio sobre el mismo.

2 Estimada, por cuanto la diferente interpretación del artículo 1 del Tratado de 1881 en lo referido al curso del límite internacional en la zona andino-patagónica, principalmente, generó una nueva controversia que se zanjó con el arbitraje de S.M. el rey Eduardo VII de Gran Bretaña (Laudo de 2 de noviembre de 1902).
Así definido en general su extendido contorno norte y oriental, el interior de Magallanes permanecía administrativamente indiviso en tanto que se mantenía virtualmente despoblado, excepción hecha de sus habitantes indígenas. Con la emergencia del fenómeno colonizador en el distrito de Magallanes oriental a contar de 1877-80; en la Tierra del Fuego desde 1880-85, en los distritos de las Islas Australes a partir de 1890 y de Última Esperanza desde 1893-94, los mismos se fueron ocupando y poblando paulatinamente, circunstancia que exigió las primeras divisiones administrativas para fines elementales de gobierno y seguridad. Surgieron así las subdelegaciones de Patagonia, Islas Australes, Última Esperanza y Tierra del Fuego.

Entre tanto así había ocurrido y ocurría los diferentes gobernadores que se habían sucedido en el mando territorial habían demandado, a partir de 1889, la creación de la Provincia de Magallanes para ajustar su vigencia a las normas constitucionales de la República, sin éxito alguno.

\section{CREACIÓN DE LAS COMISARIAS RURALES}

Tal era la situación vigente intraterritorialmente cuando Carlos Bories se hizo cargo de la Gobernación del Territorio (1898). Preocupó desde el primer momento a este mandatario la extensión del ecúmene (territorio en ocupación colonizadora) que podía estimarse grosso modo en unos 40.000 kilómetros cuadrados en la época del cambio de siglos, del XIX al XX, y que situado en general sobre la vertiente oriental de Magallanes corría desde las estribaciones meridionales de la sierra Baguales (aproximadamente 50 $50^{\prime}$ S) hasta la isla Navarino (55은 $\mathrm{S}$, con una población desperdigada sobre el mismo que podía estimarse en los comienzos del siglo XX en unos dos y medio millares de almas ${ }^{3}$. Ello está claro, debía generar situaciones referidas a la seguridad pública, más acusada en aquellos distritos en que el aislamiento de los escasos habitantes podía alentar la ocurrencia de delitos o a lo menos perturbar la normalidad de la tranquila vida rural pionera.

3 El censo nacional de 1895 había registrado 1.943 habitantes civilizados para el sector rural sobre una población total de 5.170 habitantes. La población aborigen, para entonces relictual, podía estimarse en unas 500 personas. 
Así entonces la urgencia de atender a la vigilancia de los campos, según lo consignaría después Lautaro Navarro Avaria condujo a Bories a crear en primera instancia el cargo de "comisario rural" cuyo ámbito jurisdiccional daría lugar al surgimiento de unidades administrativas menores para el mejor manejo de su extensa gobernación. Esta figura era absolutamente novedosa, como que no se ha encontrado referencia precedente ni contemporánea para la misma en el ordenamiento constitucional chileno ni en las leyes complementarias de la época.

Pero tratándose, como se trataba de un "territorio de colonización", situación de suyo excepcional en la organización administrativa de la República, podía aceptarse que se dieran en él situaciones de carácter especial con figuras administrativas ad hoc, que de algún modo conformaron un precedente para la entidad de que se trata. Fueron estos los casos del nombramiento de José Manuel Valdivieso como "Juez Comisario de la Patagonia" (Decreto 34 de 1890 de la Gobernación de Magallanes) y de Emilio Bays, en calidad de "Inspector de los animales pertenecientes a la Nación" (Decreto 237 de 2 de junio de 1890 de la misma autoridad). El primero de ellos, que diéramos a conocer hace algunos años, tenía por objeto [...] el cuidado de los terrenos fiscales baldíos; observancia de los límites de los arrendados a particulares; auxiliar a los indios patagones y en una palabra para el buen orden general de aquellas apartadas [regiones] que se encontraban completamente abandonadas ${ }^{4}$. Su ámbito jurisdiccional no fue precisado geográficamente, pero es obvio que se refería a la zona centro-oriental de Magallanes, entonces también conocida como "Patagonia Oriental Chilena”. El segundo nombramiento, más específico que el primero, tenía como objeto el de la captura de todos los animales vacunos alzados o "baguales" escapados de la antigua hacienda fiscal de Agua Fresca, lo que determinaba su campo de acción preferentemente sobre la zona central de la península de Brunswick. Para el efecto se le facultaba para contratar ocho hombres, que debían ser pagados de su peculio. El inspector nombrado se resarcía de ésos y otros gastos con una participación del cincuenta por ciento en el valor de los animales capturados.

4 M. Martinic, Los Aónikenk. Historia y Cultura (Ediciones de la Universidad de Magallanes, Punta Arenas, 1995), págs. 151 y 152.
De esa manera, cuando la autoridad territorial, en el caso el Gobernador Carlos Bories, disconforme como se hallaba por la ineficacia de la subdivisión administrativa vigente (subdelegaciones) se enfrentó a la necesidad de atender al debido control de la zona rural colonizada en cuanto decía con el orden y la seguridad públicos, la atención de algunos asuntos administrativos menores y el cumplimiento de órdenes judiciales, en fin, consideró en 1899 la institución del cargo de "Comisario Rural" 5 . Lautaro Navarro Avaria, a quien se debe la primera de las dos únicas fuentes de información que se conocen sobre la materia, nada dice sobre este acto gubernativo en su conocida obra citada, aunque sí sobre el paso siguiente acontecido en 1902, esto es, acerca de la creación de las "Comisarías Rurales" y sobre el que se hace referencia más adelante. Quien sí da una luz es Manuel Zorrilla (Magallanes en 1925, Punta Arenas, 1925), aunque de modo tan escueto como que únicamente se refiere al origen y denominación del cargo de que se trata, y al año de su institución ${ }^{6}$.

De aquí que cabe la conjetura acerca de una creación un tanto experimental en lo tocante al cargo propiamente tal y para el regimiento en zonas rurales determinadas seguramente por su población e importancia relativas en el conjunto territorial, y que debe suponerse resultó exitoso en la práctica. Así, al cabo de tres años de vigencia, la figura de que nos ocupamos se consolidó y se extendió por todo el Territorio de Magallanes mediante la segunda medida consignada.

En una suerte de legislación sobre la marcha -lo que afirma su carácter circunstancial- , aquella disposición fue seguida por otra complementaria, el decreto de 12 de abril de 1902 de la Gobernación del Territorio de Magallanes, que creó y puso en vigencia a las Comisarías Rurales. Esta resolución instituyó doce entidades de la especie, asignándoles los límites correspondientes, determinación seguida a su vez por las designaciones de los respectivos titulares de la responsabilidad.

La novedad en esta legislación menor de circunstancias, propiamente un ordenamiento administrativo, estuvo en que ello fue puesto en

5 Al parecer no hubo en el caso "una descripción del cargo", según se hace modernamente, y las facultades correspondientes debieron tomarse de la reglamentación vigente para las autoridades administrativas menores, según se verá.

6 Pág. 233. 
conocimiento de la autoridad superior, entendemos del Ministerio de Relaciones Exteriores y Colonización al que tocaba la jurisdicción sobre la materia, y de ese modo se obtuvo la aprobación por decreto supremo de 5 de julio de 1902.

El ámbito territorial de todas las comisarías se correspondía exactamente con el del ecúmene, es decir, con el sector del territorio en plan de poblamiento colonizador y que se extendía por toda la vertiente oriental de Magallanes, esto es, sobre partes de Patagonia y Tierra del Fuego (teniendo como referencia geográfica determinante el curso discontinuo N-S-SE-E de la cadena andina sobre ambos territorios) y el solo agregado del distrito de las Islas Australes, ubicado geográficamente al sur del eje andino fueguino, que en esa parte tiene curso final oeste-este.

Sobre ese territorio en pleno proceso de desarrollo que, ya se ha visto, podía estimarse en unos $40.000 \mathrm{~km}^{2}$, su población había crecido de 1.215 almas en noviembre de 1885 (primer censo nacional con registro poblacional rural para Magallanes), a 1.943 en 1895. Los siguientes recuentos, el municipal de 1906 y el nacional de 1907, registrarían respectivamente 3.206 y 4.944 habitantes. Ello significa que en veinte años la población rural se había casi triplicado (la territorial lo haría más de seis veces), no obstante lo cual la densidad era bajísima, apenas poco más de un habitante por cada 40 kilómetros cuadrados, hecho que por sí solo daba cuenta de una gran dispersión y consiguiente riesgo para la vida humana, considerando las situaciones de orden y seguridad públicos.

Para el detalle de las unidades originalmente creadas seguimos a Navarro Avaria:

I Comisaria.- Tres Puentes. Limitada al norte, el río de Chabunco; al sur, el límite urbano de Punta Arenas; al este, las aguas del Estrecho; $i$ al oeste, las cumbres de la península de Brunswick.

II Comisaria.- Cabo Negro. Limitada al norte, Cabeza del Mar i una linea que del Despuntadero corre al occidente hasta el mar de Otway; al sur, el limite norte de la II Comisaria; al este las aguas del Estrecho; i al oeste, el mar de Otway.

III Comisaria.- Rio Verde. Limitada al norte, por el paralelo 52 30'; al sur, el limite norte de la II Comisaria; al este, el meridiano 70 54': i al oeste, los bosques de la Vaqueria del Norte i el mar de Skyring.
IV Comisaria.- Morro Chico. Limitada al norte por la linea divisoria con la República Arjentina: al sur, el limite norte de la III Comisaria; al este, el meridiano 7054'; i al oeste, los bosques de la Vaqueria del Norte.

V Comisaria.- Punta Del Monte. Limitada al norte por la linea divisoria con la República Arjentina; al sur, las aguas del Estrecho; al este, el paralelo 70을 2 ; al oeste, el límite oriental de las III i IV Comisarias.

VI Comisaria.- Ciaique. Limitada al norte por la linea divisoria con la República Arjentina; al sur, las aguas del Estrecho; al este, el meridiano 69 50'; i al oeste, el deslinde con la $\mathrm{V}$ Comisaria.

VII Comisaria.- Punta Delgada. Limitada al norte por la línea divisoria con la República Arjentina; al sur, las aguas del Estrecho; al este, la punta Dungeness i límite con la República Arjentina; i al oeste, el deslinde con la VI Comisaria.

VIII Comisaria.- Última Esperanza. Comprende todos los contornos de esta rejión, deslindando por el oriente con la República Arjentina.

IX Comisaria.- Rio de los Ciervos. Formada por la parte de la península de Brunswick no comprendida en las I, II i III Comisarias.

$X$ Comisaria.- Tierra del Fuego. Comprende la parte de la isla al norte de la cordillera Sarmiento, eliminando la población de Porvenir.

XI Comisaria.- Isla Dawson. Comprende toda la isla de este nombre.

XII Comisaria.- Islas Australes. Comprende el archipiélago al sur del canal de Beagle, i la parte de la isla grande de la Tierra del Fuego al sur de la cordillera Sarmiento.

En Abril de 1904, en la Tierra del Fuego se crearon dos Comisarias, quedando la X limitada a Jente Grande i sus contornos. Las nuevas Comisarias fueron:

XIII Comisaria.- Caleta Josefina, en Bahía Inútil.

XIV Comisaria.- San Sebastian, próxima a la línea en frontera con la República Arjentina, i a la bahía de aquel nombre.

En Julio del mismo año se crearon en la península de Brunswick:

XV Comisaria.- Snug Bay. Limitada al norte por el paralelo $53^{\circ} 47^{\prime}$ '," o sea una línea que partiendo desde el Cabo San Isidro remate en 
puerto Gallant; i al este, sur i oeste con las aguas del Estrecho.

XVI Comisaria.- Cuter Cove. Limitada al norte por las aguas de Otway; al este, el $72^{\circ}$ de lonjitud; al sur, las aguas del Estrecho; $i$ al oeste, el canal Jerónimo.

XVII Comisaria.- Río San Juan. Limitada al norte por el rio de Agua Fresca; al sur por el cabo San Isidro; al este, por el Estrecho de Magallanes; $i$ al oeste, por las cumbres de la cordillera de la península de Brunswick.

Por fin, el 6 de Octubre de 1907 se creó la:

XVIII Comisaria.- Rio Baker. Limitada al norte por el paralelo 47\%; al sur, limite norte de Última Esperanza; al este, la linea divisoria con la República Arjentina; $i$ al oeste, tierras inexploradas próximas a los canales de Patagonia ${ }^{7}$.

Con posterioridad hubo una nueva modificación, al parecer a mediados de la segunda década del siglo XX y finalmente, en 1925 por decreto de fecha 27 de enero, el Gobernador Arturo E. Swett reorganizó y amplió el número de comisarías rurales, que quedó de la manera siguiente:

a) En el distrito Península de Brunswick

- 1․ Comisaría RIO SAN JUAN

- 2a . Comisaría RIO EL CANELO

- 3a. Comisaria GUAYRABO

- 4⿳亠丷. Comisaría RIO DE LOS CIERVOS

- 5a. Comisaría TRES PUENTES

- 6․ Comisaría RIO PESCADO

b) En el distrito Magallanes centro-oriental

- 7ª. Comisaría OAYZY HARBOUR

- 8a. Comisaría PUNTA DELGADA

- 9a. Comisaría SAN GREGORIO

- 10․ Comisaria TRES CHORRILLOS

- 11‥ Comisaría RIO VERDE

- 12․ Comisaría CERRO NEGRO

- 13a. Comisaría LAGUNA BLANCA

- 14․ Comisaría MORRO CHICO

- 15‥ Comisaría DINAMARQUERO

Op. Cit., tomo II págs. 441 y 442.

8 El distrito del Baker, aislado como estaba entonces del resto del territorio magallánico poblado por gente civilizada por el Archipiélago Patagónico y el gran campo del Hielo Patagónico Sur, comenzó a ser colonizado a partir de 1904. c) En el distrito de Última Esperanza

- 16ª Comisaría CERRO CASTILLO

- 17a. Comisaría RIO DE LAS CHINAS

- 18a. Comisaría ÚLTIMA ESPERANZA

(Puerto Natales)

- 19ª Comisaría RIO BAKER

d) En el distrito de Tierra del Fuego (isla grande)

- 20‥ Comisaría GENTE GRANDE

- 21a. Comisaría BAHIA FELIPE

- 22 ${ }^{\text {a }}$. Comisaría PUNTA CATALINA

- 23a . Comisaría SAN SEBASTIAN

- 24ํㅡ. Comisaría CALETA JOSEFINA

- 25a . Comisaría SANTA MARIA

e) En el distrito Isla Dawson

- 26‥ Comisaría ISLA DAWSON

f) En el distrito Islas Australes

- 27a. Comisaría ISLAS AUSTRALES ${ }^{9}$

Esta reorganización daba cuenta tanto del desarrollo interno dentro del ecúmene magallánico, cuanto de la mayor densidad poblacional.

Las comisarías rurales tuvieron vigencia en tanto Magallanes mantuvo la forma político-administrativa de Territorio de Colonización, esto es, hasta el 31 de diciembre de 1927. A partir del 1 de enero de 1928 se creó la nueva Provincia de Magallanes, con sus subdivisiones naturales en departamentos (Magallanes, Última Esperanza y Tierra del Fuego), y estos a su vez divididos en subdelegaciones y distritos de acuerdo con la Constitución de 1925, que para el caso repetía las disposiciones de la Constitución de 1833.

Y tornando a la titularidad del cargo de comisario rural, el mismo no requería más que la necesaria solvencia moral y, por cierto, alguna instrucción. El servicio tenía carácter indefinido y se prestaba en forma concejil o ad honores. Para la nominación se prefirió desde un principio a quienes ocupaban como arrendatarios campos fiscales, o bien se desempeñaban como administradores de estancias, en los casos que la arrendataria era una sociedad pastoril. Ello antes de 1903-6 (período de enajenación de los terrenos fiscales en Patagonia),

9 Manuel Zorrilla, Magallanes en 1925 (Punta Arenas, 1925), tomo II, págs. 233 y 234. 
pues con posterioridad se eligió entre los propietarios y/o administradores de predios rurales, y también, aunque de manera excepcional, a los jefes de las tenencias de carabineros cuando había presencia policial permanente (casos de las comisarías de Río Pescado, Morro Chico y Dinamarquero).

Para las funciones referidas al orden y la seguridad públicos cada comisario rural tenía a su disposición dos guardianes de la Policía Territorial.

Han podido conocerse algunos nombres de cuantos se desempeñaron como comisarios rurales durante el tiempo de vigencia de la institución, y para el caso se los menciona con la identificación de su correspondiente comisaría:

Tres Puentes, Juan Bitsch; Cerro Negro, Albán Ladouch (¿1899?-1902); Río Verde, Doode van Troostwyk (¿1899?), Enrique Wagner (1902), Jesús Osorio (1925); Morro Chico, H. Townsend (1906); Punta del Monte, John Mac Lean (1902-1907); Cabo Negro, Julio Cordonier (1903); Ciaique, George Allan (1903); Punta Delgada, H. S. Trehern; Última Esperanza, Ricardo Krüger (¿1899-1902), Mario Enrique Stuardo (1902); W. H. Morrison (1925); Río de los Ciervos, José M. Rodríguez (192..); Gente Grande, C. M Hobbs (1925); Isla Dawson, Alejo $2^{\circ}$ Marcou (1925); Islas Australes, Mariano Edwards (Islas Picton, Nueva, Lennox (1916), Emiliano Gómez (1925); Guillermo Wahlen (Islas Navarino, Hoste, Wollaston 1916); Baker, Charles Wood (¿1920?, Carlos Cramer $(1927)^{10}$.

En la nómina consignada puede observarse la predominancia de individuos de nacionalidad extranjera (principalmente británicos), circunstancia que se corresponde con la participación determinante de gente de ese origen y de otros europeos en la actividad colonizadora inicial y en la etapa de consolidación que la siguió hasta la tercera década del siglo XX.

Cabe una referencia particular para John Mac Lean Frazer, que dejó para la posteridad copia de su correspondencia durante los años de ejercicio como comisario rural de Punta del Monte, circunstancia feliz que permite conocer con detalle y precisión las tareas propias del cargo, según se trata más adelante, y a quien, con merecimiento cabal, corresponde tener para la historia como ejemplo de servicio público.

10 Los años entre paréntesis se refieren tanto al tiempo de nombramiento o bien a la constancia escrita de tal circunstancia.
Originario de Rosshire, en Escocia, donde nació entre 1860 y $1864^{11}$, salió de su patria todavía muy joven con destino a las islas Falkland. Hacia 1883, cuando sólo tenía 19 ó 23 años, reemigró a la Patagonia para trabajar en la ganadería ovina que recién se iniciaba en ese vasto territorio y, si se daba la suerte, para iniciarse como estanciero. Así fue como, encontrándose en Punta Arenas, se asoció en 1887 con un paisano, Merrick Mac Lean, para poblar una fracción de campo en Santa Cruz, Argentina. En esa preocupación se hallaba cuando el año siguiente determinó incorporarse al grupo de británicos, entre ellos Thomas Saunders, William Hope, Henry Jamieson y John Hamilton, que planeaban adquirir ovinos y caballares en la provincia de Buenos Aires para trasladarlos posteriormente hasta el sur con fines de poblamiento pastoril. Fue así coprotagonista de una faena históricamente memorable, conocida como "el gran arreo de la Patagonia".

Al cabo del mismo, Mac Lean retornó a Punta Arenas en donde continuó empeñado en introducirse en el negocio ovejero. Primero lo hizo participando en una especie de mediería con Enrique Wagner (1889), pero siempre buscando instalarse por cuenta propia, fijó su interés para ello en los campos de la zona central de Magallanes y así obtuvo en octubre de 1891 la autorización de la Gobernación del Territorio para ocupar un terreno baldío de 10.000 hectáreas en el sector conocido como Punta del Monte ${ }^{12}$, al oeste de la laguna Blanca. Ello sin perjuicio de gestionar la adquisición en propiedad de otra cantidad de campos semejantes en el sector argentino de El Zurdo, entre la frontera internacional y el río Gallegos.

En su actividad, John Mac Lean debió acreditar prestigio como hombre respetable y confiable, con vocación de servicio público, pues en 1902 el Gobernador de Magallanes, Carlos Bories, lo desig-

11 Hay dudas respecto a la fecha de su nacimiento. En efecto, aunque la descendencia señala los años 1863 ó 1864, investigaciones hechas por uno de los autores en los archivos del Civil Register of Scotland indican a 1860 como el año natal.

12 Este topónimo en el presente está virtualmente fuera de uso y sólo puede encontrárselo en los mapas y no debe confundírselo con otro homónimo ubicado al oeste de la laguna Blanca, entre los kilómetros 108 y 109 de la ruta 9 que transcurre entre Punta Arenas y Puerto Natales. El origen del topónimo está en el lenguaje propio de la gente de campo que denomina "punta" a una penetración, en el caso del bosque (monte) en la estepa. 
nó por decreto 164 de 6 de marzo Comisario de la Sección V Punta del Monte, con la responsabilidad del ejercicio de autoridad menor para varios fines administrativos y policiales.

El desarrollo de la explotación no fue fácil pues los campos de Punta del Monte no eran de los mejores para el objeto y durante sus etapas de principio y desarrollo hubo que soportar el rigor de inviernos excepcionalmente crudos, con pérdidas importantes en la dotación animal. Así, hacia fines del siglo XIX, Mac Lean decidió buscar otro lugar más propicio para iniciar un segundo establecimiento, el que encontró en el sector norte de las Llanuras de Diana, en el distrito de Última Esperanza, donde la colonización pastoril se había iniciado hacía pocos años. Allí dio comienzo a una explotación en sociedad con su hermano Murdo (1898).

Pero la situación empresarial que pintaba mejor para el colono pionero, comenzó a cambiar a partir de 1903, época en que el gobierno chileno decidió llevar a remate las tierras fiscales de Patagonia hasta entonces ocupadas por arrendatarios o meros tenedores, circunstancia que le obligó a entregar sus campos una vez que estos fueron subastados por un tercero, ya que Mac Lean no consiguió reunir el capital suficiente como para tomar parte en el remate, pues todo cuanto poseía lo tenía invertido en sus animales e instalaciones.

Concentró entonces su actividad criadora y sus intereses en la zona del lago Balmaceda que ocupaba, pero allí tampoco consiguió permanecer pues en septiembre de 1905 la Sociedad Explotadora de Tierra del Fuego remató ésos y otros campos de Última Esperanza, con los que la misma principió a consolidar el que sería a poco andar su enorme latifundio ganadero de Magallanes.

Aunque en uno y otro caso la desocupación de los terrenos explotados no fue inmediata, pues Mac Lean gozó de un plazo de gracia para ello, lo que evitó la ruina de sus correspondientes explotaciones ya castigadas por algunos inviernos excesivamente severos, hacia 1908 debió abandonarlas definitivamente. Se estableció entonces con su esposa e hijos, que ya sumaban ocho, en el incipiente caserío que se formaba junto al río Natales, futuro puerto homónimo, a cuyo desarrollo aportó instalando la primera panadería del lugar y promoviendo la apertura de una escuela particular, de la que fueron alumnos sus propios hijos.
Pero para un hombre esforzado que había vivido hasta entonces por y para la faena criadora ovejera, la forzada inactividad debió afectarlo anímicamente y fue así que se empeñó en encontrar un terreno apto para ello, aunque el mismo se situara en los lindes mismos del ecúmene territorial. Lo encontró al fin, al cabo de seis años de espera, en el sector del fiordo Erezcano en el pie oriental de la cordillera de los Andes, en donde el holding Braun \& Blanchard tenía la estancia "San Juan", cuyos derechos e instalaciones adquirió Mac Lean pagándolos con quinientas acciones de la Sociedad Explotadora de Tierra del Fuego, que su esposa Mary Ann había recibido en herencia de su padre John Cameron. El campo era, definitivamente, muy inferior en calidad a los que el pionero había poseido, no obstante lo cual John Mac Lean se aplicó a su explotación con la misma energía desplegada otrora en otros lugares.

Pero la mala suerte de antaño parecía no querer abandonarlo y fue así que en agosto de 1918 aquél demandó el amparo de la Gobernación de Magallanes para continuar con su explotación, ante una amenaza de desalojo. Ocurría que el campo en que la misma se encontraba, así como otros terrenos fiscales de la periferia del ecúmene occidental de Magallanes habían sido concedidos años antes por el Supremo Gobierno a Juan Tornero, un conocido especulador de la época, quien buscó aprovechar la ventaja que le daba su situación legal para despojar virtualmente a muchos colonos que con gran esfuerzo y no poco sacrificio habían conseguido hacer surgir explotaciones ganaderas, que recién al cabo de años podían arrojar algún resultado económico satisfactorio.

$\mathrm{Su}$ reclamo justiciero fue acogido, por el Supremo Gobierno y así la estancia "San Juan" continuó en manos del pionero escocés, que la manejó con la colaboración de sus hijos mayores hasta 1940 y que los mismos prosiguieron por algunos años más tras el fallecimiento del progenitor. Allí Mac Lean encontró al fin si no el bienestar económico que merecía, a lo menos la tranquilidad que esperaba para su numerosa familia, en especial para su querida Mary Ann Cameron Mac Call, su abnegada compañera de aventuras pobladoras (con quien había contraído matrimonio el 2 de octubre de 1894), quien falleció todavía joven, 45 años, el 21 de julio de 1920, en Puerto Natales, cuatro meses después de dar a luz a Elena Patricia Jes- 
sie, su última hija. Antes habían nacido John, en 1895(+1978), James William, en 1897(+1967), Jane Ann, en 1898(+1986), Mary Betsie, en 1900(+1990), Thomas Charles, en 1902(+1987) y Susana Edith, en 1904(+1992), todos ellos en Punta del Monte; siguieron Frank Douglas, en 1907(+1970) y Roderick Duncan, en 1908(+1996), en el sector del lago Balmaceda, y, por fin, Cluny Cave, en 1911(1951), Murdo Domingo, en 1912(+1989), Rebeca Mabel May, en 1915(+1993), Margaret Violeta Natalia, en 1917(+2009), y la mencionada Elena Patricia Jessie, quien vivió hasta 1987.

El viejo luchador, un pionero auténtico por donde se le considere y un típico hombre común británico, falleció en Puerto Natales el 27 de setiembre de 1940, gozando del afecto ciudadano, dejando en su patria de adopción una familia numerosa con un fuerte arraigo local, a la que legó tal vez como única herencia el ejemplo de su vida laboriosa, que su descendencia ha recogido y cultivado como se manifiesta en los campos del comercio y de la industria, y en el ejercicio prestigiado de las profesiones liberales, honrando así la digna memoria del fundador ${ }^{13}$.

\section{2.- FUNCIONES Y ATRIBUCIONES DEL COMISARIO RURAL}

El ejercicio de la función de un comisario rural debió tener como necesaria referencia lo correspondiente a las propias de los subdelegados $e$ inspectores de distrito que, como se sabe, ocupaban los escalones inferiores de la administración interior de la República. Las mismas pudieron ser complementadas con otras según necesidad. Así, en lo que interesa, cabe una diferenciación y descripción de las mismas sobre la base principal de la información epistolar de John Mac Lean, de igual modo como de decretos gubernativos de la época, de manera complementaria, y su cotejo con el Manual para los subdelegados e inspectores vigente en la época ${ }^{14}$.

13 En esta reseña biográfica hemos seguido en buena parte a la escrita en la obra de uno de los autores (M. Martinic, Los británicos en la Región Magallánica, Ediciones Puntángeles - Universidad de Playa Ancha - Universidad de Magallanes, Valparaíso, 2006), págs. 175-180.

14 Incluido como apéndice en el Manual para Jueces de Distrito y Subdelegación, de Robustiano Vera (Santiago, 1884), cuyo conocimiento debemos a la averiguación realizada por el señor Nelson Alvarez, que agradecemos.
De esa manera es posible mencionar funciones de carácter policial, judicial, administrativo y de orden vario.

a) Relativas la orden y seguridad públicos:

- Control de conductas y desórdenes. Tal lo sucedido en junio de 1903 cuando un tal José Torres, peón de la estancia "Dinamarquero" usó de un revólver cargado que portaba y disparó un tiro en la casa-dormitorio de los trabajadores con la consiguiente alarma del personal. En la ocasión se detuvo a Torres por portar arma de fuego cargada y disparar con ella. El responsable del desorden fue enviado a Punta Arenas, debidamente custodiado por un guardián, para ser puesto a disposición del Comisario de Policía (Comunicación de 4 de junio de 1903).

- Control de Vagancia. Ello para evitar la presencia de individuos de mal vivir en el distrito.

- Expulsión de gente indeseable del Territorio. Eso en cumplimiento de órdenes de la Policía de Punta Arenas. En los casos correspondientes el comisario rural debía facilitar la custodia policial para poner al sujeto de expulsión en la frontera internacional (Casos de Francisco Pérez y un tal "Chino Julio").

- Prevención del abigeato. Ello suponía el conocimiento de la "Guía de Marcas y Señales del Territorio" y la devolución a su dueño de todo animal encontrado. De igual modo la detención del imputado en caso de denuncia sobre robo de animales y su puesta a disposición de la Policía de Punta Arenas para los fines consiguientes.

b) Relativas al cumplimiento

de órdenes judiciales:

- Auxilio de fuerza pública. Para el debido cumplimiento de decretos del Juzgado de Punta Arenas.

- Notificaciones de embargo mercantil, incluyendo las respuestas de los afectados por las mismas.

c) Relativas a la administración:

- Información sobre defunciones. Fue el caso del que se dio cuenta por nota del 25 de noviembre de 1902 y referido al hallazgo del cadáver de M. Kogan, ovejero extraviado meses antes. La comunicación contiene la descripción acerca de la posición y estado del cadáver y de todas las especies 
que se encontraron junto al mismo o en la ropa que portaba.

- Informe sobre establecimientos comerciales abiertos en el distrito y actividades de control de su funcionamiento.

- Notificaciones sobre pagos de patentes comerciales.

- Control de caminos y de libertad de tránsito. Ello incluía la denuncia a la Gobernación del Territorio en caso de cierros de pasos y tranqueras, y la orden de apertura de caminos públicos, y de remoción de obstáculos, siempre con informe a dicha autoridad.

- Control del cumplimiento de las normas de arrendamientos prediales; notificaciones de pago de rentas atrasadas y de desahucio de contratos.

- Inscripciones civiles y otorgamiento de certificados de nacimiento.

- Control del cumplimiento de la Ley de Conscripción Militar. En el caso, información sobre persona no registrada en su oportunidad (comunicación al Gobernador y Comandante de Armas del Territorio).

\section{d) Actuaciones de carácter vario:}

- Las propias de su cargo, referidas a los guardianes de su dependencia (comunicaciones sobre pagos de haberes, licencias, reemplazos e inventario de especies a cargo tales como uniformes, arreos, armas y cabalgaduras).

- Responsabilidad del levantamiento de registros censales (demográficos) y su información posterior.

- Suministro de antecedentes sobre actividades económicas productivas en el distrito (explotaciones, animales, habitaciones y demás, y estimación de inversiones).

- Encargos especiales, como fue el recolectar semillas de plantas silvestres para el Gobernador del Territorio. La comunicación correspondiente, de 9 de abril de 1903, da cuenta del envío de semillas de roble (probablemente Nothofagus antarctica y $N$. pumilio, ambas presentes en los campos de Monte Alto que arrendaba Mac Lean; Calafate (Berberis sp.), romerillo (Chiliotrichium diffusum), "Té Patagonia" o "de Pampa" (Satureja darwinii) y murtilla (Empetrum rubrum).

Todas estas acciones, se reitera, se enmarcaban cabalmente en las facultades concedidas legal o administrativamente a los subdelegados e inspectores de distrito, tanto en lo específico, como en lo general.

\section{3.- LA COMISARIA RURAL DE PUNTA DEL MONTE}

El territorio de la comisaría Rural de Punta del Monte con su delimitación ya conocida, integraba el distrito centro-oriental de Magallanes, del que tempranamente fue uno de los sectores más conocidos por los habitantes de la Colonia de Punta Arenas. Corazón de la parte meridional del país aónikenk, allí se situaron algunos de sus paraderos más conocidos, entre ellos Horsh Aike, Nameraik, justamente famoso (devenido posteriormente por corrupción fonética en Dinamarquero) ${ }^{15}$; Juniaike y Osiaba, derivación fonética de Oazy Harbour, topónimo utilizado por los baqueanos y cuya denominación indígena, lo mismo que para el paradero de Tres Chorrillos, no se conservó. Por allí, también, transcurrían las sendas indígenas históricas, que en lo que interesa, correspondía al tramo vado de Cabeza del MarDinamarquero-Ciaike ${ }^{16}$, que vinculaba al estuario del río Gallegos (y al del Santa Cruz más al norte) en la costa atlántica, con los sectores nororientales de la península de Brunswick, entre ellos los de Cabo Negro, Punta Arenas y Puerto Famine sobre la costa continental del estrecho de Magallanes. Una segunda senda o rastrillada india derivaba del paradero Horsh hacia el oriente, rumbo de Osiaba y Kolkaike (San Gregorio) y otros parajes tradicionales del litoral fretano. Otras dos huellas utilizadas por los aborígenes y por los baqueanos eran una, la que partiendo desde Tres Chorrillos seguía rumbo hacia la laguna Blanca, por el noroeste, y otra, que saliendo desde Nameraike seguía con idéntico rumbo el cañadón del curso superior del río Susana (después también conocido como Dinamarquero), para remontar a la meseta y acceder a los campos de La Pelecha y al valle del río Gallegos Chico. Todas estas sendas eran perfectamente visibles y practicables en el tiempo del principio de la colonización pastoril.

15 Por allí pasaron entre los años 30 y 90 del siglo XIX, viajeros y exploradores tales como Arms y Coan, Schmid y Hunziker, Musters, Moreno, Lista, Beerbohm, Dixie, Rogers, Dublé Almeida y Bertrand entre otros que conocieron y trataron a jefes como Huisel, Casimiro, Papón y Mulato.

16 Bien descrito por George Musters en su libro Viaje con los Patagones (Solar Hachette, Buenos Aires, 1964), pág. 61 y notas pág. 80 . 
El buen trato que prácticamente desde el comienzo se dio entre los aónikenk y la gente de Punta Arenas, principalmente con los baqueanos, cazadores y traficantes, permitió obtener una buena y temprana noción acerca de la calidad de los campos del distrito (calificados por los valles pastosos, bien regados por numerosos arroyos y con abundancia de fauna), sobre todo aquellos ubicados en la mitad meridional. De allí que los terrenos correspondientes y por vecindad los que seguían hacia el norte estuvieron entre los primeros en ser peticionados $y$ ocupados por cuantos se interesaron en instalarse como criadores ovejeros.

Así, se sabe que el primero en establecerse fue el británico Henry Reynard, pionero iniciador de la ganadería lanar, que lo hizo hacia 1879 ocupando los campos de la bahía Oazy hacia el interior. Para 1882-83 se agregaron los establecimientos de Mateo Paravić, en Cabeza del Mar, y de Thomas Fenton, en la costa norte de Peckett Harbour y campos de la laguna Casimiro. Es claro que esos terrenos se ocuparon primeramente por su condición litoral pues el acceso más practicable entonces, como lo sería por largo tiempo después, para el movimiento de personas, animales y cargas era la vía marítima. La forma utilizada para el asentamiento fue la de simples permisos de ocupación, por tanto de carácter precario, en una tenencia que comenzó a regularizarse a fines de 1884 tras el primer remate de arrendamiento de campos fiscales. En lo que al área de la futura comisaría concernía, los rematantes fueron Carlos Felton (Cabeza del Mar), Patrick Ryan (Bahía Peckett), Thomas Fenton (Laguna Casimiro), Henry Reynard y Edgard S. Yonge (Bahía Oazy), totalizando en conjunto 140.000 hectáreas.

Luego, a contar de 1885 la expansión colonizadora se manifestó sobre los campos del interior. Tales los casos de José Fiol (Dinamarquero), Mauricio Braun (Laguna Romero), Michael Doolan, Otto Seeger, Dolores Dómine y José M. Valdivieso en la zona fronteriza de Gallegos Chico. Para mediados de 1902, época para la que se cuenta con información particularizada proporcionada por el comisario Mac Lean, los arrendatarios de campos del distrito eran la sucesión del Dr. Thomas A. Fenton (Laguna Casimiro, antiguos lotes 31 y 32); Henry Reynard (Bahía Oazy, id. id. 33 y 34); John Mac Lean (Punta del Monte, antiguo lote 46); Mauricio Braun y John Cameron (Dinamarquero y Laguna
Romero, que correspondían a los lotes originalmente numerados 45, 48, 49 y s/n; Murdo Finlayson (id. id. 46 y 56), José Menéndez, arrendatario de los lotes 47 y 51, y Michael Doolan (lote antiguo 52), todos en el sector de Gallegos Chico; y finalmente Frayssenau y Cía. arrendatarios de los campos de Panteón (lote 54).

La importancia de estos establecimientos (estancias) estaba dada por los siguientes antecedentes según la información pasada por el comisario Mac Lean a la Gobernación del Territorio:

\begin{tabular}{|l|rrr|c|}
\hline \multicolumn{1}{|c|}{ Arrendatario } & \multicolumn{3}{|c|}{ Dotación Animal } & $\begin{array}{c}\text { Avalúo } \\
\text { Instalaciones }\end{array}$ \\
\hline & Ovejas & Vacas & Caballos & \\
\hline $\begin{array}{l}\text { Suc . Fenton \& } \\
\text { Waldron }\end{array}$ & 46.000 & 90 & 130 & $\$ 300.212,50$ \\
\hline $\begin{array}{l}\text { Henry Reynard } \\
\text { (Roig \& Cía. }\end{array}$ & 72.000 & 300 & 350 & $456.860,--$ \\
\hline John Mac Lean & 2.800 & 28 & 130 & $36.760,--$ \\
\hline Braun y Cameron & 36.000 & 60 & 680 & $319.935,--$ \\
\hline M. Finlayson & 3.000 & 8 & 110 & $22.757,75$ \\
\hline José Menéndez & 3.000 & 23 & 60 & $35.637,50$ \\
\hline M. Doolan & 3.000 & 11 & 12 & $23.425,62$ \\
\hline Frayssenau y Cía. & 6.000 & 15 & 108 & $42.343,75$ \\
\hline
\end{tabular}

Puede observarse de lo expuesto que los tres establecimientos principales (Reynard, Fenton y Braun \& Cameron) representaban el 90\% de las inversiones y de la dotación de ganado del distrito, conjunto en el que destacaba la estancia "Oazy Harbour" fundada por el introductor de la ganadería ovina en la Patagonia, el pionero Henry L. Reynard, que por sí sola reunía el 40\% de la inversión productiva (casas, galpones, maquinarias, cercos y demás) y alrededor del $42 \%$ de la dotación animal (ovinos, bovinos y caballares). Era, lejos, un establecimiento modelo para la época, en el que inclusive -cosa excepcional- las condiciones de vida y de trabajo de los obreros eran de calidad superior, tanto como para que James Radburne, que trabajó allí ocasionalmente entre 1894 y 1900 denominara a sus trabajadores "caballeros ovejeros".

Esa era una estancia modelo respecto a todo. Hasta los ranchos de los ovejeros en Oazy Harbour eran confortables casas campestres de ladrillos y las condiciones de sus trabajadores eran tales que en la Patagonia se les conocía como los "caballeros ovejeros", los que hasta recibían carbón para la cocina y la calefacción, recordaría cuarenta 


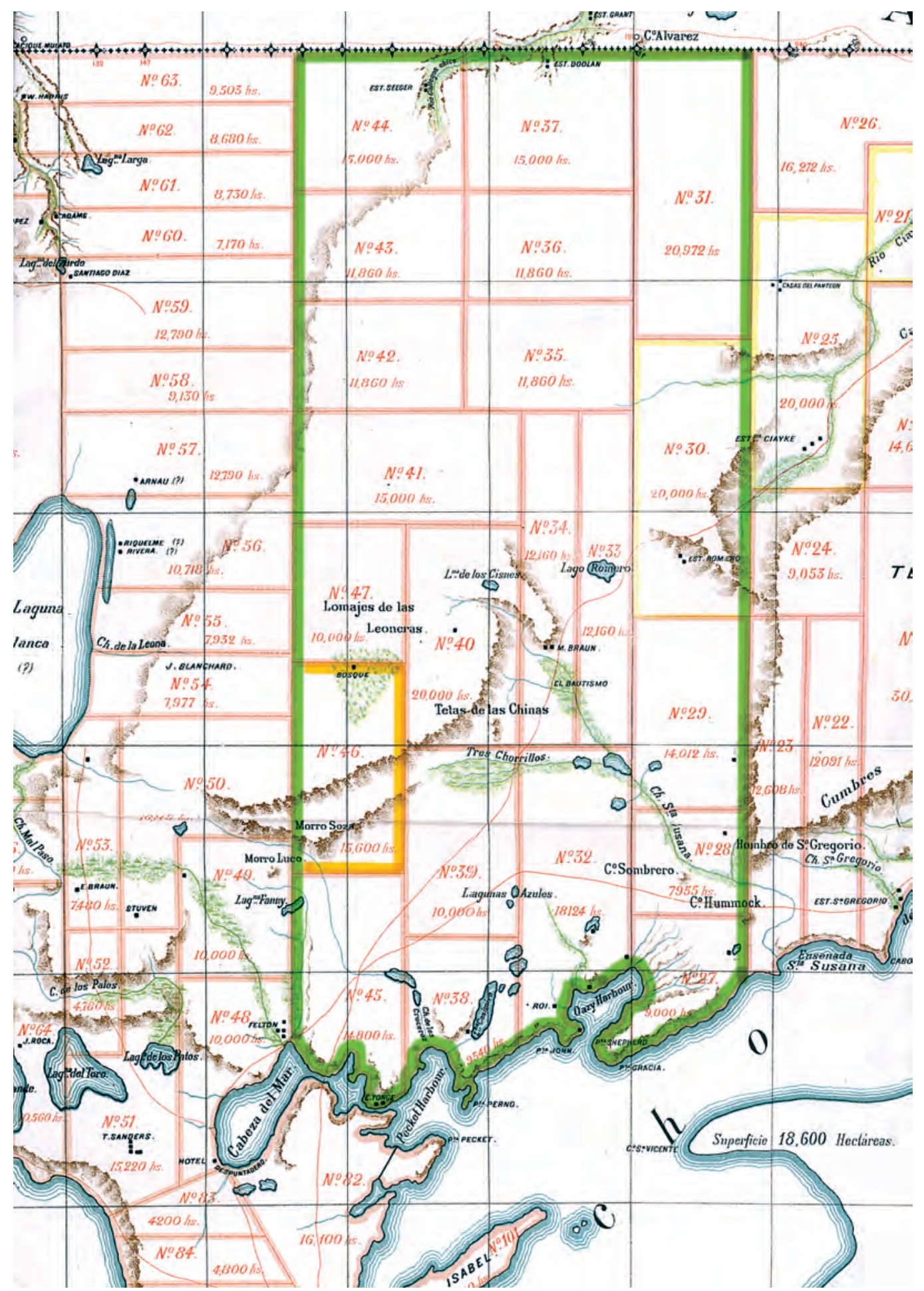

Fig. 1. Área de la Comisaría Rural de Punta del Monte (en recuadro verde).

Tomado del "Plano Topográfico de la Hijuelación de los Terrenos Fiscales de Magallanes 1902". (Escala 1:250.000) por Alvaro Donoso. 
años después aqué ${ }^{17}$. Todo un ejemplo que expresa cabalmente la calidad humana del pionero ${ }^{18}$.

La modesta inversión de Menéndez en el distrito, por otra parte, se explica por el hecho de que la principal estaba en su gran estancia "San Gregorio" se encontraba en los campos vecinos del sector homónimo.

En los campos libres del distrito y aún sobre parte de los ocupados situados entre Dinamarquero y Gallegos Chico, que se correspondían con las zonas más altas, deambulaban libremente los aónikenk todavía hasta mediados de la década final del siglo XIX y sin ser molestados por los colonos, aunque cada vez en menor número por causa de su ya irreversible declinación étnica. Pudo vérselos así por sus antiguos campos de caza y de paso por los paraderos tradicionales tanto en los campos litorales como en los del interior siempre en una interrelación amistosa con los foráneos, excepción hecha de un solo caso de agresión en su contra ${ }^{19}$.

Además de la presencia colonizadora mencionada y de los aborígenes, el solo hecho de transcurrir por el distrito la antigua vereda indígena principal ya mencionada, devenida camino vecinal de importancia y como tal cada vez más utilizado en cuanto intercomunicaba a Punta Arenas con los campos del oriente magallánico continental y con el territorio argentino del Atlántico, fue razón suficiente para que a su vera se instalaran hoteles rurales, en verdad pequeños centros de abastecimiento ocasional y de alojamiento para pasajeros, como de sitio de entretenimiento y sociabilidad para la peonada rural. Tal sucedió en los parajes Pozo de la Reina y Laguna Romero, donde los primeros hoteles fueron abiertos por el norteamericano Henry Meade y el británico Charles Finger, respectivamente, seguidos años después por el croata Blas Martinovic con su hotel de Cruceros, en el sector que pudo corresponder con el antiguo paradero aónikenk de Horsh.

17 En Herbert Childs, El Jimmy, Bandido de la Patagonia (Ediciones de la Universidad de Magallanes, Punta Arenas 1997), pág. 69.

18 En este aspecto cabe recordar el conceptuoso texto de la lápida funeraria dedicada a uno de sus trabajadores y que firmó como "Su patrón y amigo H. L. Reynard", mención absolutamente excepcional para la época y que, otra vez, pone de manifiesto su nobleza de alma (Martinic 1995).

19 Caso del colono Alfonso Vilageliú que adquirió los intereses de su compatriota José Fiol cuando éste retornó a España (Cfr. M. Martinic, Los Aónikenk, Historia y Cultura (Ediciones de la Universidad de Magallanes, Punta Arenas 1995, pág. 154.
Para el cambio de siglos, del XIX al XX, la crianza ovina no sólo había demostrado su adaptabilidad a las condiciones ambientales de la Patagonia y la Tierra del Fuego, sino que, además, se había manifestado como una fuente de riqueza personal para los colonos que habían intentado su explotación. De allí que al acercarse la época de vencimiento de los arrendamientos de campos, las autoridades y organismos del Estado advirtieron el interés generalizado por acceder a la explotación de los campos pastoriles tanto por la vía mencionada, o bien por la venta de terrenos, modalidad que sería la elegida, con la variante de su realización en subasta pública, decisión controvertida y resistida por los antiguos arrendatarios que reclamaron, inútilmente, la preferencia en el derecho a la compra por haber sido quienes los habían puesto en valor. Para ello, oportunamente, se dispuso la mensura e hijuelación definitiva (originalmente había una provisoria) de los campos disponibles en Patagonia (Magallanes centro-oriental y Última Esperanza), concluidas las cuales el Congreso Nacional aprobó la ley que facultaba la enajenación.

Las subastas (tres) se realizaron entre los años 1902 y 1906, circunstancia que permitió la constitución de la propiedad rural en Magallanes. En lo tocante al área de la Comisaría de Punta del Monte, los rematantes (1902 y 1906) fueron los siguientes:

\begin{tabular}{|l|l|l|}
\hline $\begin{array}{l}\text { Número } \\
\text { de Lote }\end{array}$ & Superficie & \multicolumn{1}{|c|}{ Rematante } \\
\hline 28 & 7.955 has. & Sociedad Ganadera de Magallanes \\
\hline 29 & 14.012 has. & Sociedad Ganadera de Magallanes \\
\hline 30 & 20.000 has. & Pastor Infante para S.G. Mags. \\
\hline 31 & 20.972 has. & Eugenio Bois de Chesne \\
\hline 32 & 18.124 has. & Sociedad Ganadera de Magallanes \\
\hline 33 & 12.160 has. & Sociedad Ganadera de Magallanes \\
\hline 34 & 12.160 has. & Mauricio Braun \\
\hline 35 & 11.860 has. & Sociedad Ganadera de Magallanes \\
\hline 36 & 11.860 has. & Sociedad Ganadera de Magallanes \\
\hline 37 (a y b) & 15.000 has. & F. Vives (J. Menéndez) y M. Braun \\
\hline 38 & 9.540 has. & $\begin{array}{l}\text { Jorge Wood } \\
\text { (S. Criaderos de Casimiro) }\end{array}$ \\
\hline 39 & 10.000 has. & Emilio Alemparte (J. Menéndez) \\
\hline 40 & 20.000 has. & Francisco Roig (Rodolfo Suárez) \\
\hline 41 & 15.000 has. & Sociedad Ganadera de Magallanes \\
\hline 42 & 11.860 has. & Sociedad Ganadera de Magallanes \\
\hline 43 & 11.860 has. & Sociedad Ganadera de Magallanes \\
\hline 44 (a y b) & 15.000 has. & Mauricio Braun y José Menéndez \\
\hline 45 & 14.800 has. & Jorge Wood (S. C. de Casimiro) \\
\hline 46 & 15.600 has. & Emilio Alemparte (J. Menéndez) \\
\hline 47 & 10.000 has. & Soc. Ganadera de Magallanes \\
\hline
\end{tabular}


Puede advertirse en el listado precedente la ausencia del nombre de Reynard. En efecto, el mismo estuvo entre los perdedores en las subastas, circunstancia que hubo de dolerle especialmente tanto por lo que había hecho en su explotación, cuanto porque en tanto que pionero fundador de la crianza ovina consideró que bien se merecía el premio de la propiedad de los campos que había hecho productivos con su creatividad, su tesón y su capital.

De la información consignada se aprecia asimismo que por la mecánica del remate, las tierras quedaron en pocas manos, originándose de esa manera el latifundio que caracterizaría a la economía ganadera magallánica hasta la séptima década del siglo XX. La concentración fundiaria se produjo en el transcurso de la segunda mitad de la primera década del siglo y culminó en 1910 con la adquisición que hizo la Sociedad Explotadora de Tierra del Fuego -la empresa pastoril más poderosa del Territorio- del activo y pasivo de la Sociedad Ganadera de Magallanes, la rival que le había surgido en suelo continental. A partir de entonces y hasta 1970 la situación de dominio de los campos del distrito de que se trata se concentró en las manos de dos personas naturales, inicialmente, y de las de tres sociedades, según se indica:

\begin{tabular}{|c|c|c|}
\hline Establecimiento & Propietario & $\begin{array}{c}\text { Dotación } \\
\text { Ovina }\end{array}$ \\
\hline $\begin{array}{c}\text { Estancia "Oazy Harbour" } \\
\text { (lotes 27, 28, 29, 30, 32, } \\
\text { 33, 35, 36, 41, 42, 48) }\end{array}$ & $\begin{array}{c}\text { Soc. Explotadora de } \\
\text { Tierra del Fuego. }\end{array}$ & $\begin{array}{c}288.597 \\
\text { cabezas }\end{array}$ \\
\hline Estancia "Fenton" (lote 45) & $\begin{array}{c}\text { Soc. Criaderos de } \\
\text { Casimiro Ltda. }\end{array}$ & $\begin{array}{c}25.000 \\
\text { cabezas }\end{array}$ \\
\hline $\begin{array}{c}\text { Estancia "Tres } \\
\text { Chorrillos" (lote 40) }\end{array}$ & Rodolfo Suárez & $\begin{array}{c}12.000 \\
\text { cabezas }\end{array}$ \\
\hline $\begin{array}{c}\text { Estancia "Dinamarquero" } \\
\text { (lotes 34, 37b, 44a) }\end{array}$ & $\begin{array}{c}\text { Mauricio Braun } \\
\text { (después S.E.T.F.) }\end{array}$ & $\begin{array}{c}30.000 \\
\text { cabezas }\end{array}$ \\
\hline $\begin{array}{c}\text { Estancia "Avelina" } \\
\text { (lotes 39 y 46) }\end{array}$ & $\begin{array}{c}\text { Soc. An. Gan. Com. } \\
\text { Menéndez Behety }\end{array}$ & $\begin{array}{c}20.000 \\
\text { cabezas }\end{array}$ \\
\hline $\begin{array}{c}\text { Estancia "Gallegos } \\
\text { Chico" (lotes 37a, 44b) }\end{array}$ & $\begin{array}{c}\text { S.A.G.C. Menéndez } \\
\text { Behety }\end{array}$ & $\begin{array}{c}9.000 \\
\text { cabezas }\end{array}$ \\
\hline \multicolumn{2}{|c}{} & \multicolumn{2}{|c|}{}
\end{tabular}

En cuanto al lote 31 (Gallegos Chico) hacia fines de los años de 1920 su propiedad estaba dividida por mitades entre The Patagonian Sheep Farming Company y S.A. Ganadera Argentina Carlota.
La tenencia pecuaria total en la propiedad fundiaria así concentrada y excepción hecha de la correspondiente al lote 31, representaba entonces el 18,5\%, 8\% y 15\% de las dotaciones ovinas, bovinas y equinas estimadas para el Territorio de Magallanes en 1919 (2.071.516 ovejas, 13.916 vacunos y 13.502 caballos). La misma no variaría sensiblemente en la década de vigencia que restaba a las comisarías rurales.

Cabe, finalmente, para la más acabada caracterización de lo que fuera la Comisaría Rural de Punta del Monte, dar cuenta de su demografía durante el período histórico de que se trata. Los antecedentes censales correspondientes revelan que su población fue siempre escasa en relación con el total registrado para las zonas rurales de Magallanes -históricamente bajo-, con un elevado componente masculino en su población, que, de haber sido absoluto en un principio llegaría a la proporción de tres hombres por cada mujer en 1930, señal expresiva, a su vez, de la reducida cantidad de familias radicadas.

Los registros conocidos son los siguientes:

Censo Municipal 190682 habitantes

Censo Nacional $1907 \quad 150$

Censo Nacional $1920316 \quad$ " (268 h. 52 m.)

Censo Nacional $1930384 \quad$ “ (288 h. 96 m.)

Además de los recuentos consignados, el comisario Mac Lean realizó uno especial en 1904 que arrojó la cantidad de 208 habitantes, cifra muy superior a la censal de dos años después, diferencia que se explica por la gran demanda de mano de obra requerida por las construcciones realizadas en los diferentes establecimientos luego de los remates; vale decir que se trató de una presencia temporal excepcional. No se poseen datos sobre la población rural registrada en los censos anteriores a 1906 (nacionales de 1885 y 1895), pero sobre la base del municipal podría estimarse una población permanente de un par de decenas de personas en el primer caso, considerando que la colonización recién se iniciaba, y de un medio centenar en el segundo, como cálculos mínimos. Su escasa relevancia en el ámbito rural territorial está dada por su baja participación relativa que fue apenas igual al 0,25\% en 1906 y a $0,40 \%$ en $1930^{20}$.

20 En 1906 la población rural registrada fue de 3.206 habitantes y en 1930 de 8.261 para todo Magallanes. 
Cabe abundar con alguna información sobre la procedencia étnica de los habitantes del distrito de Punta del Monte, siquiera para los años finales del siglo XIX, época para la que se cuenta con antecedentes. Aunque, como es de esperarlo, había entre ellos gente de diferente nacionalidad, hubo en ciertos momentos de la empresa colonizadora una notoria presencia de extranjeros por sobre la de chilenos, que pudo ser abrumadora en el tiempo inicial del proceso poblador e importante siempre, especialmente aquella conformada por gente de habla inglesa (británicos y otros). En ausencia de un registro censal conocido de carácter específico ${ }^{21}$ viene al caso en subsidio una referencia que puede ser validada como de buena aproximación. Se trata de las noticias que entregara un ovejero de la época, James Radburne, quien vivió en el distrito entre 1894 y $1900^{22}$.

En efecto, en su relato se hacen reiteradas menciones a personas, 49 en total, de las que 35 eran de extracción anglosajona (33 británicos, 2 norteamericanos y un australiano); 7 chilenos, 2 españoles, 2 austríacos, 2 argentinos y un indio norteamericano ("Long Alec", de etnia gayhead) que se desempeñaba como cocinero en la estancia "Oazy Harbour". Este antecedente confirma otros datos que se han manejado en diferentes trabajos de uno de los autores (Martinic 1973, 1975, 1976, 1988, $1995,2005,2006$ y 2007) y a la correspondiente conclusión en lo tocante a que tanto la población como la fuerza de trabajo rurales tuvieron el principio de la colonización (1878) y el término de su primera fase (1902), un elevado componente de británicos. El caso de Punta del Monte, por lo tanto, conforma una referencia particular que confirma la regla.

Así descrita en sus características, la Comisaría Rural de Punta del Monte puede ser tenida para el conocimiento histórico como el exponente típico, en tanto su actividad y población, de un sistema de explotación latifundiaria con su correlato social de infrapoblamiento y ello como natural consecuencia

21 La publicación oficial referida al censo nacional de 1907 desagrega la población rural por nacionalidad pero agrupándola por distritos más amplios, entre los que estaba el denominado "Patagonia" y que debe entenderse como el que reunía a las comisarías rurales de Río Verde, Morro Chico, Punta del Monte, Ciaique y Punta Delgada. En el mismo se había registrado un $41 \%$ de la población como de origen extranjero.

22 En Chils op. cit. de las condiciones ambientales para un mejor uso económico, según la modalidad productiva adoptada.

\section{PANORAMA DE LA VIDA COTIDIANA RURAL EN EL COMIENZO DE LA COLONIZACION PASTORIL}

La vida campesina, en especial la referida a la gente común (ovejeros, puesteros, peones), en la Patagonia austral y la Tierra del Fuego ha sido una materia a la que, en general, se ha prestado escasa atención por parte de los investigadores, como lo mencionáramos en fecha reciente (Martinic 2009). Esto es así principalmente por la escasa información primaria de que ha podido disponerse pues quienes fueron protagonistas o testigos de tal vivencia no siempre dejaron constancia escrita sobre la misma y si tal hicieron, los documentos correspondientes conocidos son contados. De allí que toda nueva información debe ser bien recibida, máxime si procede de fuentes hasta ahora inéditas como es el caso de la correspondencia epistolar de John Mac Lean, concerniente a los años 1902 a 1907, y de la que es posible extraer o inferir con fundamento noticias sobre la materia que, sumadas a otros antecedentes, permite iluminar mejor lo que debió ser la existencia en el ámbito rural magallánico durante la etapa colonizadora inicial, comprendida entre 1878 y 1903.

Ello importa porque no sólo hace posible conocer con algún grado de detalle la forma en que se fue ocupando el extenso territorio estepario -parte principal del ecúmene-, sino, lo que más interesa, el modo en que los foráneos, esto es, la gente no aborigen, se fueron habituando a un medio natural particularmente exigente y rudo hasta concluir adaptándose definitivamente al mismo y asumiendo tal modalidad al cabo de una vida en él, como algo propio.

Iniciada una explotación pastoril, la oferta de trabajo así abierta se refirió necesariamente a la propia de la crianza ovejera, principalmente en toda su variedad de tareas históricamente conocidas (cuidado y manejo en corrales, arreo, esquila, carneo, etc.), y a la relacionada de carácter permanente u ocasional (faenas de alambrado, apertura de pozos, acequias $y$ picadas en terrenos de monte, construcciones varias, cocina, en fin). Tocante al primer aspecto, si importante era la ocupación con las ovejas, base de toda explotación ganadera, no lo era menos el 
requerido por la caballada que toda estancia debía tener para atender con mayor eficacia aquel aspecto esencial y en ello la marca y doma de animales era una faceta tan importante como interesante del trabajo y la vida rurales. El entrenamiento y manejo de los perros ovejeros, en tanto que elemento de faena indispensable, también fue cosa relevante.

Así explicado, el trabajo abundó en el tiempo del inicio de la colonización para quien arribado a Punta Arenas lo buscara y lo encontrara en el ámbito rural, o bien, si se atrevía, esperando encontrarlo a la buena ventura deambulando sin rumbo fijo por las llanuras esteparias del oriente magallánico. Encontrada la ocupación, sólo restaba aceptar el salario ofrecido, conformarse con la reciedumbre de la faena campesina y la rusticidad de la vida cotidiana, y trabajar duro procurando algún sentido a la existencia teniendo en miras un futuro mejor. Va de suyo que la remuneración iba en relación directa con los conocimientos que tenía el que deseaba empleo: mejor paga si sabía de las faenas de campo, o lo que se ofreciera, si no. Ello, en cualquier caso conllevaba una movilidad entre estancia y estancia, tránsito laboral determinado por los distintos caracteres de las personas involucradas: el del propio interesado, o de cada patrón o administrador, y aun por el de los capataces o cocineros, con quienes la interacción debió ser por fuerza mayor y frecuente. Fue común incluso que quien habiéndose iniciado en un establecimiento prestigiado como hubo de ser la estancia "Oazy Harbour" de Henry Reynard, y alejado del mismo por cualquier razón que no fuera la expulsión, retornara en demanda de nueva ocupación. En este aspecto el distrito de Punta del Monte ofrecía alternativas en sus contadas estancias que pasaron a integrar una suerte de circuito laboral (principalmente "Fenton", "Oazy Harbour", "Dinamarquero").

Si lo laboral era un aspecto esencial de la vida campesina, no lo era menos la sociabilidad en un territorio extenso y escasamente poblado. En ella, en la certidumbre de que no se estaba solo, había que alternar, gustara o no, con gente de diferente laya, nacionalidad, lengua y cultura, y adaptarse a los compañeros permanentes u ocasionales hubo de ser la norma clave para una existencia soportable. Una buena alternativa para socializar, cambiar de ambiente y echar una cana al aire la brindaban los hoteles rurales desde temprana época (Pozo de la
Reina y Laguna Romero inicialmente y Cruceros, con posterioridad en lo que al distrito se refiere). En este particular la única fuente informativa disponible hasta ahora es Radburne (en Childs op. cit.), aunque suficiente por demás para la materia.

Otra posibilidad de relación debió darse entre los trabajadores rurales y los aónikenk, pues estos indígenas durante los años de 1880 y 1890 continuaron frecuentando los campos meridionales de su antiguo solar en tanto las circunstancias y en especial su menguante número lo fueron permitiendo. Las referencias diversas, en Childs desde luego y muy importantes, en particular para el sector de Dinamarquero y aledaños, pero también en Bertrand (1886) y Agustín Del Castillo (1883), además de algunas pocas noticias recogidas por la tradición. De esta relación han quedado inclusive testimonios arqueológicos históricos, como lo diéramos a conocer en 1991. La misma debe ser tenida como una relación habitualmente pacífica y amistosa entre los foráneos y el declinante mundo aborigen que parecía entender la inevitabilidad de la coexistencia en el amplio ámbito sudpatagónico. Está visto que ambas formas de sociabilidad, fueran buscadas o casuales, siempre debieron ser bienvenidas como circunstancias que alternaban el agobio de la rutina, la soledad y el relativo aislamiento.

En otro aspecto, la vida rural estaba signada por la austeridad y la frugalidad. La gente campesina común no tenía sino lo puesto o poco más, esto es, la ropa que se vestía (y que se cambiaba cuando se disponía de algún dinero en los boliches de campo o de las estancias); algunos objetos de utilidad práctica y, si el salario lo permitía, el infaltable caballo -medio de transporte personal por excelencia- la montura, demás aperos, incluido el lazo, y un par de perros, si es que se tenía la especialidad ovejera. Precisamente en este aspecto del vivir campesino el comisario Mac Lean aporta un dato inestimable que confirma nuestra apreciación previa, al dar cuenta inventariada de lo encontrado en o junto al cadáver de un tal Kogan, al parecer ovejero británico hallado muerto en noviembre de 1902 y que se había dado por perdido desde varios meses antes:

Un reloj "Longines" Grand Prix Paris 1889; una cadena de chaleco con una moneda de un shilling; un cortaplumas; un cuchillo de campo; una cachimba; tabaco en plancha; un lápiz; 20 centavos 
en moneda; un pito de lata; un pañuelo colorado (para el cuello); un paquete de diarios y un par de botas altas de cuero.

En el contexto de un vivir austero como era la norma de la época entre la gente de campo esta relación nos informa sobre un individuo que parecía haber tenido algún cuidado en su persona (botas altas, pañuelo, reloj y cadena), lo que sugiere un tiempo de trabajo suficiente como para disponer de dinero para esos "lujos"; que era fumador (pipa y tabaco), que poseía alguna instrucción y que aparentemente se interesaba por el acontecer del mundo (diarios). El cuchillo y el cortaplumas, el primero en especial, eran elementos indispensables de variada utilidad y aún para la defensa personal para cualquier hombre de campo. Respecto del pito, el mismo era un adminículo simple utilizado por los ovejeros para el manejo de los animales con la ayuda de los perros.

La retribución para la que debió ser obligada escasez de recursos del trabajador rural en la época colonizadora, hubo de darse en el agrado de la vida libre y el placer de la aventura en tierras de frontera -debe tenerse presente que los protagonistas fueron casi sin excepción hombres jóvenes-, magras compensaciones que no obstante hicieron tolerable la existencia rural magallánica y que permiten entender el casi paradojal sentimiento de afecto por la tierra yerma y hosca -pero atractiva al fin ${ }^{23}$ - que hubo de generarse entre los que por gusto o por necesidad se afincaron en ella, con una fuerza tal que trascendería a los protagonistas para incorporarse finalmente al ethos social de la región.

\section{AGRADECIMIENTOS}

Agradecemos especialmente a los señores Sergio y John Mac Lean Gómez la voluntad para facilitar el conocimiento del Copiador de Cartas de su bisabuelo John, así como al señor Nelson Alvarez por su preocupación en la obtención de antecedentes referidos a las atribuciones de las antiguas autoridades administrativas inferiores. Del mismo modo se agradece la colaboración de la señora Gladys-Grace Paz por la lectura crítica del trabajo y sus sugerencias para mejorarlo.

23 Recordamos en este respecto el dicho popular, "la fea cuando enamora, enamora hondo".

\section{FUENTES DE CONSULTA}

a) Inéditas

Copiador de cartas de John Mac Lean (1902-1920).

Copiador de Decretos Gobernación de Magallanes Marzo 1887-octubre11890. Archivo de Documentos Inéditos, Centro de Estudios del Hombre Austral, Instituto de la Patagonia, Universidad de Magallanes.

Copiador de Decretos Gobernación de Magallanes Setiembre 1896-octubre 1897. Id. id. id.

Copiador de Decretos Gobernación de Magallanes Junio de 1902-Abril 1903. Id. id. id.

b) Impresas

CAMPBELL, DUNCAN S. 2006 Juan Mac Lean, comisario honorario: correspondencia oficial, 1902-1906. En http://patlibros.org/jmc

CRAMER, JORGE A. 2006. Por si quede. Historias de pobladores y viajeros en la Patagonia Austral contados en el fogón por ellos mismos. Photo Design Ediciones Buenos Aires.

CHILDS, HERBERT. 1997 (1936). El Jimmy, Bandido de la Patagonia. Ediciones de la Universidad de Magallanes. Punta Arenas.

MARTINIC B. MATEO. 1973. Panorama de la colonización en Tierra del Fuego entre 1881 y 1900. Anales del Instituto de la Patagonia, vol. 4:5-69. Punta Arenas. -1975. Origen y desarrollo de la inmigración extranjera en la Colonia de Magallanes entre 1870 y 1890. Anales del Instituto de la Patagonia, vol. 6:5-41. Punta Arenas.

-1976. La ganadería lanar en Magallanes en su primer cuarto de siglo 1877-1902. Anuario Corriedale de Magallanes 1976:4-29. Punta Arenas.

-1978. Exploraciones y colonización en la Región Central Magallánica 1853-1920. Anales del Instituto de la Patagonia, vol. 9:5-42. Punta Arenas.

-1988. La inmigración europea en Magallanes 1891-1920.

Anales del Instituto de la Patagonia, vol. 18:11-34.

Punta Arenas.

-1991. Hallazgo de un asentamiento colonizador en la costa de Bahía Santiago (Estrecho de Magallanes). Evidencia de relación pionero-indígena. Anales del Instituto de la Patagonia, Serie Ciencias Sociales, vol. 20:45-56. Punta Arenas.

-1995. Los Aónikenk, Historia y Cultura. Ediciones de la Universidad de Magallanes. Punta Arenas. 
-1995. Cementerios y tumbas rurales en Magallanes. Anales del Instituto de la Patagonia, Serie Ciencias Humanas, vol. 23:5-40. Punta Arenas.

-2006. Los británicos en la Región Magallánica. Ediciones Puntángeles-Universidad de Playa Ancha-Universidad de Magallanes. Valparaíso.

NAVARRO AVARIA, LAUTARO. 1908. Censo Jeneral del Territorio de Magallanes, 2 tomos. Punta Arenas.

VERA, ROBUSTIANO. 1884. Manual para Jueces de Distrito y Subdelegación. Santiago.

ZORRILLA, MANUEL. 1925. Magallanes en 1925. Punta Arenas. c) Cartografía

BERTRAND, ALEJANDRO. 1885. Plano Topográfico de la Rejión Central Magallánica. Escala 1:500.000. Santiago.

DONOSO, ALVARO. 1902. Plano Topográfico de la Hijuelación de los terrenos fiscales en el Territorio de Magallanes. Santiago.

MINISTERIO DE FOMENTO. DEPARTAMENTO DE TIERRAS Y COLONIZACION. 1928. Plano de parte del Territorio de Magallanes con la subdivisión de las tierras. Escala 1:500.000. Santiago. 
M. MARTINIC Y D. CAMPBELL 